\title{
A Study on the Coordinated Development of Virtual Economy and Real Economy
}

\author{
Wu Ailing ${ }^{1, ~ a ~, ~ L i u ~ Q i o n g ~}{ }^{1, b}$, He Tian ${ }^{2, c}$ \\ ${ }^{1}$ Harbin Institute of technology, Weihai, Shandong, China \\ ${ }^{2}$ Tianjin Commercial University, Tianjin, China \\ awuailing@hit.edu.cn, ${ }^{b}$ liuqionghit@hotmail.com, chetian99@126.com
}

Keywords: Real economy; Virtual economy; Coupling Coordination degree

\begin{abstract}
The uncoordinated development of virtual economy and real economy will cause potential risks to the economy. The real economy is the cornerstone of economic development, and the phenomenon of "real to virtual" will lead to insufficient motive force and increased risk of economic development. In order to ensure the healthy operation of the economy, promote the successful transformation of the real economy, "virtual to real" will be an important task of economic development at present. Based on relevant theoretical research, this paper analyzes the development of virtual economy and real economy from 2000 to 2018 and constructs the coupling degree and its coordination correlation model. Then it analyzes the coupling coordination degree of virtual economy and real economy and gives the relevant suggestions.
\end{abstract}

\section{Introduction}

At present, the overcapacity lead to the decline of the return on investment in the real economy and the phenomenon of "real to virtual" appears. This phenomenon continues to evolve, it will lead to the risk of crisis. The central bank has forced financial institutions to leverage by raising interest rates and strengthening the evaluation system, which define the objectives of serving the real economy. But real economic development is not optimistic. The virtual economic sectors represented by financial industry tend to be sensitive to economic policies, while real economy is slow, which leads to a time lag between the financial tightening and the transformation of real economy, and the development of virtual economy and real economy is not enough. Tobin (1984) [1] put forward hypothesis of financial instability. Gaddy (1998) [2] held that virtual economy and real economy are interact with each other. Qin Xiao (2009) [3] divided real and virtual economy according to whether there are direct transactions between the financial assets and the production of products. Liu Yang (2015) [4] believed that the deviation between virtual economy and real economy will have impacts on the financial crisis. Luo Laijun (2016) [5] considered that the financing did not enter real economy, it continues to stay in virtual economy. Liu Jie et al. (2019) [6] put forward that more attention should be paid to the transformation of economic growth mode and the adjustment of industrial structure.

In summary. It has become a fact that the deviation between virtual and real economy will have a negative impact on China's economic development. This paper analyzes the development of virtual economy and real economy from 2000 to 2018, constructs the coupling degree and its coordination correlation model, analyzes the development of virtual economy and real economy.

\section{Sources of Data and Variable Selection}

\subsection{Source of Data}

The data in this paper come from the National Bureau of Statistics, the statistical yearbook of each year and all kinds of data released by the people's Bank of China.

\subsection{Variable Selection}

It can be seen from the relevant literature that the coupling relationship between virtual economy and real economy is a complex nonlinear relationship. Xu Dilong et al. (2014) [7] construct the evaluation 
index system of virtual economic from the total index, stock index, flow index and proportion index of money market, capital market, financial derivatives market and real estate market. Su Zhi et al. (2017) [8] considered that the scale of virtual economy is mainly determined by stock market and real estate market. The construction index should revolve around the connotation of virtual economy, which takes capitalization pricing as the core and mainly focuses on the financial industry and real estate industry. The basis of comprehensive relevant literature research, this paper aims at ensuring the comprehensiveness and scientific nature of the index as much as possible, fully considers the availability of the index data, and divides the measurement index as shown in Table 1.

Table 1 Index selection of coupling coordination degree between virtual economy and real economy

\begin{tabular}{ccc}
\hline system & First index & Secondary index \\
\hline \multirow{2}{*}{$\begin{array}{c}\text { virtual } \\
\text { economy } \\
\text { indicators }\end{array}$} & $\begin{array}{c}\text { Real estate } \\
\text { indicators }\end{array}$ & $\begin{array}{c}\text { Market Capitalization, the ratio of Market Capitalization to the GDP, Share } \\
\text { turnover, Shanghai (securities) composite index, Bond turnover, Fund turnover }\end{array}$ \\
\cline { 2 - 3 } & $\begin{array}{c}\text { Value-added Index of the Real estate (last year = 100), } \\
\text { The Ratio of Value-added of the Real estate to GDP }\end{array}$ \\
\cline { 2 - 3 } $\begin{array}{c}\text { financial institutions } \\
\text { indicators }\end{array}$ & $\begin{array}{c}\text { Loans from financial institutions, the ratio of loans from financial institutions to } \\
\text { GDP, the balance of real estate loans }\end{array}$ \\
economy & $\begin{array}{c}\text { Sub-industry } \\
\text { structure indicators }\end{array}$ & $\begin{array}{c}\text { The ratio of value-added of Agriculture, forestry, animal husbandry and fishery to } \\
\text { GDP, the ratio of value-added of construction industry to GDP, } \\
\text { The ratio of value-added of industry to GDP. }\end{array}$ \\
\cline { 2 - 3 } & $\begin{array}{c}\text { Total composition } \\
\text { indicators }\end{array}$ & $\begin{array}{c}\text { Total import and export of goods, total investment in fixed assets, total retail sale of } \\
\text { consumer goods }\end{array}$ \\
\hline
\end{tabular}

\section{Model Construction and Empirical Analysis}

\subsection{Econometric Model}

\subsubsection{Measurement of the Comprehensive Development Index}

In this paper, SPSS22.0 is used to analyze the standardized processing indexes of virtual and real economy, and the weights of each index are determined. Use the linear weight method to calculate the comprehensive development index of real and virtual economy for 2000-2018, the formula is:

$$
C D I_{1}(\mathrm{x})=\sum_{i=1}^{\mathrm{n}} w_{i} x_{i} \quad C D I_{2}(\mathrm{y})=\sum_{j=1}^{n} w_{j} y_{j}
$$

Among them, CDI1, CDI2 represents the comprehensive development index of virtual economy and real economy respectively, wi, wj represents the weight of each index to measure the development of virtual economy and real economy respectively, xi, yj is the standardized value.

3.1.2 Coupling coordination degree model

The coupling coordination degree model is constructed to judge the coordinated development between virtual economy and real economy.

(1) Calculate the coupling degree of virtual economy and real economy $\mathrm{C}$ :

$$
C=\left\{\frac{C D I_{1}(x) \times C D I_{2}(y)}{\left[\frac{C D I_{1}(x)+C D I_{2}(y)}{2}\right]^{2}}\right\}^{\frac{1}{2}}
$$

(2) Calculate the comprehensive development index of virtual and real economic system CDI:

$$
C D I=\alpha_{1} C D I_{1}+\alpha_{2} C D I_{2}, \quad \alpha_{1}+\alpha_{2}=1
$$

(3) The calculation expression of coupling coordination degree is as follows:

$$
C^{\prime}=\sqrt{C \times C D I} \quad C^{\prime \prime}=\exp \left(-\frac{1}{C^{\prime}}\right)
$$




\subsection{Empirical Analysis}

According to the principal component analysis and the comprehensive development index model, the weights of each index and the comprehensive development index of the two systems are calculated in table 2 and 3 as following:

Table 2 Index system and weight calculation results of the virtual economic and real economy

\begin{tabular}{|c|c|c|c|}
\hline \multicolumn{2}{|l|}{ virtual economic } & \multicolumn{2}{|l|}{ real economy } \\
\hline indicators & weight & indicators & weight \\
\hline Market Capitalization & 0.1066 & \multirow{4}{*}{$\begin{array}{l}\text { The ratio of value-added of } \\
\text { Agriculture, forestry, animal } \\
\text { husbandry and fishery to GDP }\end{array}$} & \multirow{4}{*}{0.1661} \\
\hline the ratio of Market Capitalization to the GDP & 0.0870 & & \\
\hline Share turnover & 0.0891 & & \\
\hline Shanghai (securities) composite index & 0.0198 & & \\
\hline Bond turnover & 0.0959 & \multirow{2}{*}{$\begin{array}{l}\text { the ratio of value-added of } \\
\text { construction industry to GDP }\end{array}$} & \multirow{2}{*}{0.1495} \\
\hline Fund Turnover & 0.1016 & & \\
\hline Value-added Index of the Real estate & 0.0803 & \multirow{2}{*}{$\begin{array}{l}\text { The ratio of value-added of } \\
\text { industry to GDP }\end{array}$} & \multirow{2}{*}{0.1653} \\
\hline the ratio of value-added of the Real estate to GDP & 0.1013 & & \\
\hline Financial institutions deposit loans & 0.1121 & Total import and export of goods & 0.1693 \\
\hline the ratio of loans from financial institutions to GDP & 0.1112 & gross fixed asset formation & 0.1752 \\
\hline the balance of real estate loans & 0.1101 & total retail sale of consumer goods & 0.1746 \\
\hline
\end{tabular}

Table 3 Comprehensive Development Index of Virtual economy and Real economy from 2000 to 2018

\begin{tabular}{cccccc}
\hline Year & virtual economy & the real economy & Year & virtual economy & the real economy \\
\hline 2000 & 1.1004 & 1.0521 & 2010 & 1.4298 & 1.5072 \\
\hline 2001 & 1.0902 & 1.0671 & 2011 & 1.3509 & 1.5794 \\
\hline 2002 & 1.1090 & 1.0936 & 2012 & 1.3908 & 1.6489 \\
\hline 2003 & 1.1390 & 1.1282 & 2013 & 1.4384 & 1.7238 \\
\hline 2004 & 1.1363 & 1.1251 & 2014 & 1.5797 & 1.7952 \\
\hline 2005 & 1.1092 & 1.1759 & 2015 & 1.8152 & 1.8327 \\
\hline 2006 & 1.1365 & 1.2303 & 2016 & 1.8028 & 1.8757 \\
\hline 2007 & 1.2085 & 1.2839 & 2017 & 1.8581 & 1.9327 \\
\hline 2008 & 1.2132 & 1.3371 & 2018 & 1.8476 & 1.9798 \\
\hline 2009 & 1.3624 & 1.4440 & & & \\
\hline
\end{tabular}

According to coupling coordination degree model, the coupling coordination degree of real and virtual economy from 2000 to 2018 is obtained. By seeking the table of coupling coordination grade classification and judging its coupling coordination degree level, the results are shown in Table 4 .

Table 4 Coordination degree and type of coupling between virtual economy and real economy from 2000 to 2018

\begin{tabular}{cccccc}
\hline Year & $\begin{array}{c}\text { coupling } \\
\text { coordination }\end{array}$ & Grade degree & Year & $\begin{array}{c}\text { coupling } \\
\text { coordination }\end{array}$ & Grade degree \\
\hline 2000 & 0.3805 & Mild maladjustment & 2010 & 0.4390 & Weak maladjustment \\
\hline 2001 & 0.3814 & Mild maladjustment & 2011 & 0.4400 & Weak maladjustment \\
\hline 2002 & 0.3854 & Mild maladjustment & 2012 & 0.4467 & Weak maladjustment \\
\hline 2003 & 0.3908 & Mild maladjustment & 2013 & 0.4539 & Weak maladjustment \\
\hline 2004 & 0.3903 & Mild maladjustment & 2014 & 0.4650 & Weak maladjustment \\
\hline 2005 & 0.3934 & Mild maladjustment & 2015 & 0.4771 & Weak maladjustment \\
\hline 2006 & 0.4001 & Weak maladjustment & 2016 & 0.4790 & Weak maladjustment \\
\hline 2007 & 0.4093 & Weak maladjustment & 2017 & 0.4843 & Weak maladjustment \\
\hline 2008 & 0.4140 & Weak maladjustment & 2018 & 0.4865 & Weak maladjustment \\
\hline 2009 & 0.4309 & Weak maladjustment & - & - & \\
\hline
\end{tabular}

\subsection{Results Analysis}

As shown in the table3, the comprehensive development index of China's virtual economy and real economy generally increased from 2000 to 2018. Due to the serious impact of the financial crisis on the economy in 2008, the comprehensive development of virtual economy was slow, and declined in the later period. After 2016, the central bank and other departments issued a series of policies to promote the economy to get rid of falsehood to reality, and the excessive expansion of virtual economy moderated. According to table 4,the coupling coordination degree of virtual economy and 
real economy is rising from 2000 to 2018 , and the coupling degree of the two is higher in the process of calculation, which indicates that the interaction between the two in economic development is obvious, and the coordinated contribution to economic development increases gradually, but the coordination degree of the two is still on the low side and only reaches the weak maladjustment.

\section{Conclusion and Suggestion}

By constructing the coupling coordination degree model of virtual economy and real economy from 2000 to 2018 and carrying out empirical research, this paper analyzes the coordinated development of virtual economy and real economy in China. It is found that the coupling coordination degree between virtual economy and real economy is rising but still on the low side, from 0.3805 in 2000 to 0.4865 in 2018. The coupling degree between virtual and real economy is high, which indicates that the interaction between the two is more obvious, and the contribution to the economic development is improved as a whole. Based on the conclusion, this paper makes suggestions as following:

(1) Rely on technology and strengthen Innovation, promoting the successful transformation of the real economy, it is necessary to solve the problem of insufficient power for the development of emerging industries and overcapacity in traditional industries that the real economy could develop and prosper more. The virtual economy should be based on the principle of serving the real economy.

(2) Improve analysis on the countermeasure of government intervention policy improvement in present real estate market and financial market. The two markets are sensitive to the change of policy and form, and the real economy often has certain delay, so it should make full use of big data, artificial intelligence and other technology to analyze the financial market and give feedback to the real economy, which led to stimulate the economic growth.

\section{Acknowledgment}

Harbin Institute of Technology philosophy and social sciences prosperity project (project no. : hit.hs s.201869) : a study on the causes of the systemic risk of China\&apos;s virtual economy from the pe rspective of marxist virtual capital theory;

Research and innovation fund project of Harbin Institute of Technology, weihai city: research on dy namic evaluation and risk prediction of sustainable development of blue economic zone based on st ate space model

\section{References}

[1] Tobin. On the Efficiency of the Financial System[J].Lloyds Bank Review, 1984, (153): 112-125.

[2] Gaddy C G, Ickes B W. Russia's Virtual Economy[J]. Foreign Affairs,1998,77 (5) :53-67.

[3] Qin Xiao. China's economy-policy choice and recovery management in the post-crisis period [J]. Chinese and foreign entrepreneurs. 2009 (Z1): 52 -59.

[4] Liu Yang. A study on the influence of the deviation between virtual economy and real economy on modern financial crisis [J]. Economic problems, 2015 (01): 23-26+88.

[5] Luo Laijun, Jiang Cheng, Wang Yazhang. Financing discrimination, market distortion and profit loss-also on the influence of virtual economy on real economy [J]. Beijing: economic Research, 2016, (4): 74-88.

[6] Liu Jie, Chen Baofeng, Wu Liyun. "De-realization-to-virtual" and "De-virtual" Analysis based on Dynamic Macroeconomic Effect[J]. Business Research, 2019(04):3142.

[7] Xu Dilong, Xue Meirong. Construction of virtual economic development evaluation index system and test of measurement effect [J]. Forum on Statistics and Information, 2014: 3 -7. 
[8] Su Zhi, Fang Tong, Yin Libo. The relationship between China's Virtual economy and Real economy: an empirical study from the Perspective of scale and cycle [J]. Chinese Social Sciences, 2017(08):87-109+205-206. 